\title{
EVALUATION OF ANTIOXIDANT, A-GLUCOSIDASE AND A-AMYLASE INHIBITORY ACTIVITIES OF ATALANTIA RACEMOSA AND SENNA UNIFLORA LEAVES
}

\author{
ADHAV RAHUL*, DEOKULE SUBHASH \\ Department of Botany, Savitribai Phule Pune University, Pune, Maharashtra, India. Email: rahuluop@gmail.com
}

Received: 16 September 2017, Revised and Accepted: 30 January 2018

\begin{abstract}
Objective: The current investigation was conducted to investigate the total phenol, total flavonoid content, antioxidant, $\alpha$-glucosidase, and $\alpha$-amylase activities in leaves of Atalantia racemosa and Senna uniflora.

Methods: Different crude solvent extracts were prepared and concentrated using rotary evaporator, these solvent extracts were tested to estimate the antioxidant radical scavenging activity using 1,1-diphenyl-2-picryl-hydrazyl (DPPH) and 2, 2'-azinobis, 3-ethylbenzothiazoline-6-sulfonic acid (ABTS) methods using spectrophotometer. The extracts were screened by $\alpha$-amylase inhibition assay and $\alpha$-glucosidase inhibition assay to estimate the antidiabetic potential of the studied plant with the help of microplate reader.
\end{abstract}

Results: A potent antioxidant activity, i.e. mean percentage inhibition of DPPH and ABTS radical was observed in A. racemosa ethanol (71.5 $\pm 0.026 \%$ ) and ethyl acetate extract $(97.3 \pm 0.076 \%)$, respectively, at the concentration of $400 \mu \mathrm{g} / \mathrm{mL}$. Similarly, highest $\alpha$-amylase and $\alpha$-glucosidase inhibitory activities were observed in $A$. racemosa methanolic $(82.4 \pm 0.016 \%)$ and ethyl acetate $91.1 \pm 0.018$ extracts, respectively.

Conclusions: The present study revealed that the A. racemosa extracts possessed good antioxidant, $\alpha$-amylase and $\alpha$-glucosidase inhibitory activities; hence, it can be used as a source of natural free radical scavenger and antidiabetic supplement(s). However, further study needs to be carried out to know the active compound and its mode of action.

Keywords: Atalantia racemosa, Senna uniflora, $\alpha$-Amylase, $\alpha$-Glucosidase, Antioxidant activity.

(C) 2018 The Authors. Published by Innovare Academic Sciences Pvt Ltd. This is an open access article under the CC BY license (http://creativecommons. org/licenses/by/4. 0/) DOI: http://dx.doi.org/10.22159/ajpcr.2018.v11i5.22579

\section{INTRODUCTION}

Diabetes mellitus (DM) has turned out to be one of the major and emerging public health problems of the world. There has been perpetuating increase in the number of diabetic patients almost in all countries, especially in India, which disreputably got nicknamed as the "diabetes capital of the world [1]." DM is not a disease, but a heterogeneous group of symptoms endorsing an endocrine disorder being driven by a defective and deficient process of insulin secretion or it is a group of metabolic alterations characterized by hyperglycemia caused by insulin secretion defects, action, or both and characterized by chronic hyperglycemia or increased blood glucose level with disturbances in carbohydrates, fat, and protein metabolism resulting from absolute or relative lack of insulin secretion [2]. It is estimated approximately 285 million people worldwide or $6.6 \%$ adults have diabetes, $70 \%$ of whom live in low- and middle-income countries. This number is expected to increase by more than $50 \%$ in the next 20 years if prevention programs are not put in place [3]. DM can be classified into two major categories, i.e., Type 1 DM (T1DM) and Type 2 (T2DM). T1DM is often genetically-associated and immune-mediated and often referred to as juvenile diabetes is insulin dependent [4]. Individuals with T1DM have an absolute deficiency in insulin secretion and can be identified by serological evidence of autoimmune-mediated destruction of pancreatic islets or by genetic markers. The most common type of diabetes, T2DM, accounts for $90-95 \%$ of those with diabetes. Individuals in this category can either have a predominantly insulin resistance with relative insulin deficiency [5].

Regardless of the type of diabetes, patients are required to control their blood glucose levels with medications and/or by adhering to an exercise program and a diet plan. The conventional available therapies for diabetes include stimulation of endogenous insulin secretion (sulfonylureas and meglitinides), insulin sensitizer (metformin and thiazolidinediones), oral hypoglycemic agents such as biguanides and sulfonylureas, and the inhibition of degradation of dietary starch by glycosidase enzymes such as $\alpha$-amylase and $\alpha$-glucosidase by inhibitors (miglitol and acarbose) [6,7]. However, they have prominent side effects and fail significantly to alter the causes of diabetic complications [8]. Synthetic $\alpha$-glucosidase inhibitors (e.g., voglibose) cause's hepatic disorders and various negative gastrointestinal symptoms at high dose as carbohydrates blocked from absorption in the small intestine are fermented by bacteria in the colon [9].

Atalantia racemosa weight ex. Hook. is a small evergreen tree, belongs to family Rutaceae. An ethnopharmacological literature survey revealed that the plant has been traditionally used in the treatment snake bite [10], itching of skin, paralysis, and chronic rheumatism [11]. A. racemosa leaves decoction is used in the treatment of bronchitis, asthma and cough, bronchi, and blood purifier [12]. Senna uniflora (Mill.) H. S. Irwin and Barneby belong to family Caesalpiniaceae. The leaves are used as poultices for wounds. The roots are used for combating dropsy [13]. A decoction of laxative of $A$. racemosa mature leaves is also useful in curing ringworm and skin diseases . The poultice of the leaves is applied to wounds and the extract of the leaves is reported to cure eczema. The roots are used to combat dropsy [15].

Despite being a long tradition of use for the treatment of various ailments, no systematic pharmacological work has not been carried out so far on this potentially useful plant. Thus, the present investigations were planned with an objective to evaluate the antioxidant activity in methanol, ethanol, chloroform, and ethyl acetate solvent extracts of the plant using 1,1-diphenyl-2-picryl-hydrazyl (DPPH) and 2, 2'-azinobis, 3-ethylbenzothiazoline-6-sulfonic (ABTS) methods. Further, $\alpha$-glucosidase and $\alpha$-amylase inhibitory assays were performed to evaluate the antidiabetic potential of $A$. racemosa and $S$. uniflora. The present study will be helpful to the species knowledge and due to the 
presence of antioxidant and antidiabetic inhibitory activities, in human health applications as well as in pharmaceuticals industries, herbal medical practitioners; bush doctors (Vaidoos) and researchers.

\section{METHODS}

Plant materials were collected from in and around Pune district. Efforts were made to collect plant material in flowering and fruiting conditions for the correct botanical identification. The collected plants were identified with the help of the flora of the presidency of Bombay [16], Flora of Maharashtra State Vol I [17]. The identified plants were authenticated from the authorities of Botanical Survey of India (Ref. No. BSI/WRC/IDEN.CER./2017/Dated 24-05-2017), Pune-1, Maharashtra state.

\section{Preparation of extracts}

Freshly collected plant samples (50 g) were chopped and placed in the filter paper (No. 89) in a classical Soxhlet apparatus and successively extracted with $170 \mathrm{~mL}$ of chloroform, ethanol, methanol, and ethyl acetate solvents for $3 \mathrm{~h}$. Extracts were cooled at room temperature. The extracts were filtered through Whatman filter paper No. 1, and the filtrate was concentrated under reduced pressure by the rotary evaporator. These extracts were used in the present study.

\section{DPPH free radical scavenging activity}

DPPH radical scavenging activity was determined according to the method of Tekao et al. [18] adopted with suitable modifications [19]. The DPPH (Hi-Media) stock solution was prepared in methanol to achieve the concentration of $1 \mathrm{mg} / \mathrm{mL}$. Dilutions of plant extracts in various solvents were made to obtain concentrations of $100-400 \mu \mathrm{g} / \mathrm{mL}$. Diluted plant extracts $(1 \mathrm{~mL}$ each) were allowed to react with $1 \mathrm{~mL}$ of a methanolic solution of DPPH in the concentration of $1 \mathrm{mg} / \mathrm{mL}$ at room temperature. After $30 \mathrm{~min}$ incubation in darkness at room temperature $\left(23^{\circ} \mathrm{C}\right)$, the absorbance values were measured spectrophotometrically at $517 \mathrm{~nm}$ against the blank [20]. Control sample contained all the reagents except the extract. Percentage inhibition was calculated using equation $=[(\mathrm{A}$ control - A sample) $/$ A control] $\times 100$, where A control is the absorbance of negative control and A sample is the absorbance of the reaction mixture, while inhibitory concentration $50\left(\mathrm{IC}_{50}\right)$ values were estimated from the \% inhibition versus concentration plot, using a non-linear regression algorithm. Ascorbic acid was used as positive control. The lower the $\mathrm{IC}_{50}$ value indicates high antioxidant capacity. All tests were performed in triplicate.

\section{ABTS free radical scavenging activity}

ABTS radical scavenging activity was performed by following the method of Re et al. [21] with some modifications. ABTS (Hi-Media) radical cation was produced by reacting ABTS stock solution $7 \mathrm{mM}$ with $2.45 \mathrm{mM}$ potassium persulfate (final concentration) by dissolving in distilled water (1:1) ratio and allowing the mixture to incubate $16-20 \mathrm{~h}$ for the formation of ABTS radical cation at room temperature [22]. Before use, this solution was diluted with ethanol to get an absorbance of 0.700 at $734 \mathrm{~nm}$.

Dilutions of plant extracts in various solvents were made to obtain concentrations of $100-400 \mu \mathrm{g} / \mathrm{mL}$. The plant extract at various concentrations with $1 \mathrm{~mL}$ of ABTS solution was homogenized and its absorbance was recorded spectrophotometrically (Sican 2301, Inkarp). At $734 \mathrm{~nm}$. with the help of spectrophotometer(Sican 2301, Inkarp) by keeping ethanol as a blank. Trolox was used as positive control. As for the antiradical activity, ABTS scavenging activity was expressed as $\mathrm{IC}_{50}$ $(\mu \mathrm{g} / \mathrm{mL})$. The percent inhibition of ABTS radical scavenging activity was calculated using the following formula: ABTS scavenging activity $(\%)=$ $(\mathrm{A} 0-\mathrm{A} 1) / \mathrm{A} 0 \times 100$ where $\mathrm{A} 0$ is the absorbance of the negative control, and $\mathrm{A} 1$ is the absorbance of the sample.

\section{Determination of $\alpha$-amylase inhibitory activity}

The $\alpha$-amylase inhibitory activity was measured by following the method of Adisakwattana et al. [23] with some modification. Porcine pancreatic $\alpha$-amylase (4 units/ml) MP Biomedicals (Cat. No: 191239) was dissolved in $0.1 \mathrm{M}$ phosphate buffer saline, pH 6.9 [24]. Plant extracts stock solutions for inhibition assay in various solvents were made to obtain concentrations of $100-400 \mu \mathrm{g} / \mathrm{mL}$ and were added to a solution containing starch $(1 \mathrm{~g} / \mathrm{L})$ and phosphate buffer $(165 \mu \mathrm{L})$. The reaction was initiated by adding an enzyme solution $(75 \mu \mathrm{L})$ to the incubation medium. After $10 \mathrm{~min}$ of incubation, the reaction was terminated by adding $250 \mathrm{~mL}$ dinitrosalicylic (DNS) reagent (1\% 3, 5- DNS acid, $0.2 \%$ phenol, $0.05 \% \mathrm{Na}_{2} \mathrm{SO}_{3}$, and $1 \% \mathrm{NaOH}$ in aqueous solution). The mixtures were heated at $100^{\circ} \mathrm{C}$ for $10 \mathrm{~min}$ to stop the reaction. Thereafter, $250 \mu \mathrm{L}$ of $40 \%$ potassium sodium tartrate solution was added to the mixtures to stabilize the color. After cooling to room temperature, the absorbance was recorded at $540 \mathrm{~nm}$ using a microplate reader (EnSpire ${ }^{\circledR}$ Multimode Plate Reader). Acarbose was used as positive control.

Inhibitory activity was expressed as inhibition \% and was calculated as follows:

$$
\% \text { inhibition of } \pm \text {-amylase }=\frac{(\text { Absorbance of control)- }}{\text { (Absorbance of sample })} \times 100
$$

etermination of $\alpha$-glucosidase inhibitory activity

$\alpha$-glucosidase inhibitory activity was measured using p-nitrophenyl a-D-glucopyranoside as the substrate [25]. $\alpha$-glucosidase (Sigma Chemical Co St. Louis M.O. USA) solution (0.006\%) was prepared in $0.02 \mathrm{M}$ phosphate buffer ( $\mathrm{pH} 6.3)$. The enzyme solution $(0.13 \mathrm{~mL})$ was incubated with extract $(0.13 \mathrm{~mL})$ and $0.02 \mathrm{M}$ phosphate buffer $\left(0.45 \mathrm{~mL}\right.$ for $1 \mathrm{~h}$ at $\left.25^{\circ} \mathrm{C}\right)$. After preincubation, $2 \mathrm{M}$ p-nitrophenyl o-Dglucopyranoside $(0.67 \mathrm{~mL})$ was added to the reaction mixture. The mixture was then incubated for another $30 \mathrm{~min}$ at $30^{\circ} \mathrm{C}$. The reaction was terminated by adding $1 \mathrm{M} \mathrm{Na}_{2} \mathrm{CO}_{3}$ solution $(2 \mathrm{~mL})$. Determination of the amount of p-nitrophenol formed was read using a microplate reader at $405 \mathrm{~nm}$ [26].

Inhibitory activity was expressed as inhibition \% and was calculated as follows:

(Absorbance of control)-

$\%$ inhibition of \pm -glucosidase $=\frac{\text { (Absorbance of sample) }}{\text { (Absorbance of sample) }} \times 100$

\section{Determination of IC $_{50}$ values}

Regression equations were prepared from the concentrations of the extracts and percentage inhibition in different systems of the assay. $\mathrm{IC}_{50}$ values (concentration of inhibitor sample required to inhibit) were calculated from these regression equations. A lower $\mathrm{IC}_{50}$ value indicates higher inhibitory activity.

\section{Statistical analysis}

The results were analyzed for statistical significance by one-way ANOVA, differences of $\mathrm{p}<0.05$ were considered statistically significant. Results were expressed as mean \pm SE using the GraphPad prism 5 version (Bonferroni).

\section{RESULTS AND DISCUSSION}

\section{DPPH free radical scavenging activity}

The DPPH radical scavenging assay was done for all the four solvent extracts of ethanol, methanol, chloroform, and ethyl acetate. In the present study, the inhibition percentage and $\mathrm{IC}_{50}$ values ranges from $24.3 \pm 0.015$ to $71.5 \pm 0.026$ and $0.9 \pm 0.015$ to $13.3 \pm 0.036 \mu \mathrm{g} / \mathrm{mL}$, respectively, inhibition percentage and $\mathrm{IC}_{50}$ values are depicted in Table 1. Among the four different concentrations of standard ascorbic acid $(100,200,300$, and $400 \mu \mathrm{g} / \mathrm{mL})$ used in the study showed $70.3 \%, 87.1 \%, 89.6 \%$, and $96.5 \%$ scavenging activity, respectively, where highest scavenging activity was recorded as $96.5 \pm 0.025 \%$ at $400 \mu \mathrm{g} / \mathrm{mL}$ concentration Fig. 1 . Both plants, A. racemosa as well as $S$. uniflora, exhibited an antioxidant activity in a dose-dependent manner. The ethanolic leaf extract of $A$. racemosa exhibited higher antioxidant activity $71.5 \pm 0.026 \%$ as compared to $S$. uniflora leaf. 
ABTS free radical scavenging activity

The four solvent extracts and standard tested for in antioxidant activity using the ABTS method. In the present study, the inhibition percentage and $\mathrm{IC}_{50}$ values ranges from $20 \pm 0.075$ to $97.3 \pm 0.076$ and $2.0 \pm 0.022$ to $3.8 \pm 0.020 \mu \mathrm{g} / \mathrm{mL}$, respectively, inhibition percentage and $\mathrm{IC}_{50}$ values are depicted in Table 2. Among the four different concentrations of standard trolox $(100,200,300$, and $400 \mu \mathrm{g} / \mathrm{mL})$ used in the study showed $72.7 \%, 78.0 \%, 83.8 \%$, and $91.7 \%$ scavenging activity Fig. 2, respectively, where highest scavenging activity was recorded as 91.7 at $400 \mu \mathrm{g} / \mathrm{mL}$ concentration (Table 2). Both plants, $A$. racemosa as well as $S$. uniflora, exhibited an antioxidant activity in a dose-dependent manner. The ethyl acetate extract of $A$. racemosa exhibited higher antioxidant activity $97.3 \pm 0.076 \%$ with $\mathrm{IC}_{50}$ value $2.0 \pm 0.022$ as compared to $S$.

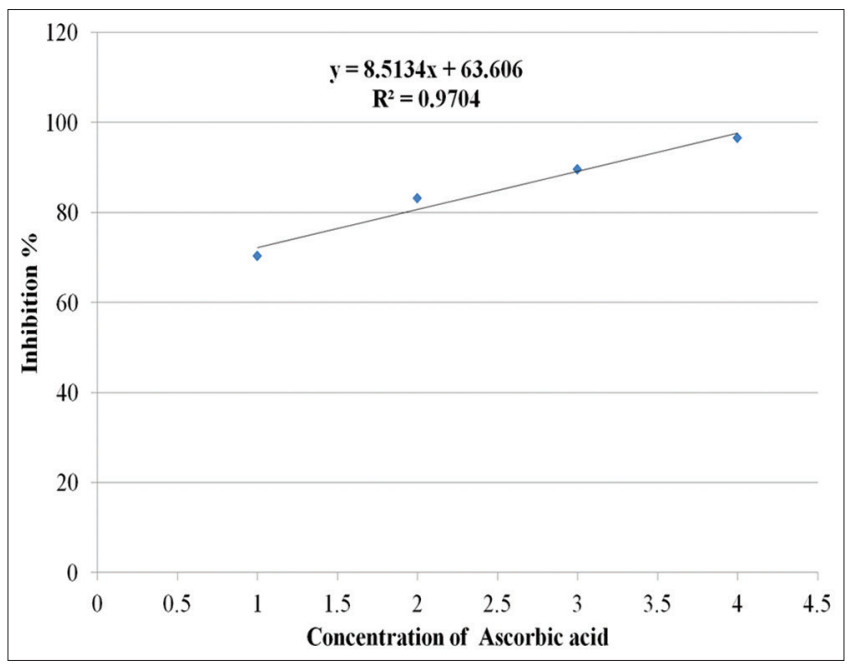

Fig. 1: Standard curve of extinction against ascorbic acid concentration uniflora leaf. However, the $S$. uniflora ethyl acetate extract was found to be more active than the standard trolox.

\section{$\alpha$-amylase inhibitory activity}

In the present study, the inhibitory activities of the selected plant species extract on the rat intestinal $\alpha$-glucosidase were determined with various concentrations $(100-400 \mu \mathrm{g} / \mathrm{mL})$. Acarbose was used as a standard reference drug Fig. 3, which showed $\alpha$-amylase inhibitory activity $83 \pm 0.017 \% \mu \mathrm{g} / \mathrm{ml}$ with an $\mathrm{IC}_{50}$ value $0.7 \pm 0.015$ at $400 \mu \mathrm{g} / \mathrm{mL}$ concentration (Table 3 ). The methanol extracts of $A$. racemosa (at a concentration $400 \mu \mathrm{g} / \mathrm{mL}$ ) exhibited highest $\alpha$-amylase inhibitory activity $82.4 \pm 0.016 \%$ with $\mathrm{IC}_{50}$ value $0.5 \pm 0.015 \mu \mathrm{g} / \mathrm{mL}$ compared with S. uniflora extracts and standard acarbose. It was also observed that the proportionate increases in the percentage of $\alpha$-amylase inhibition by an

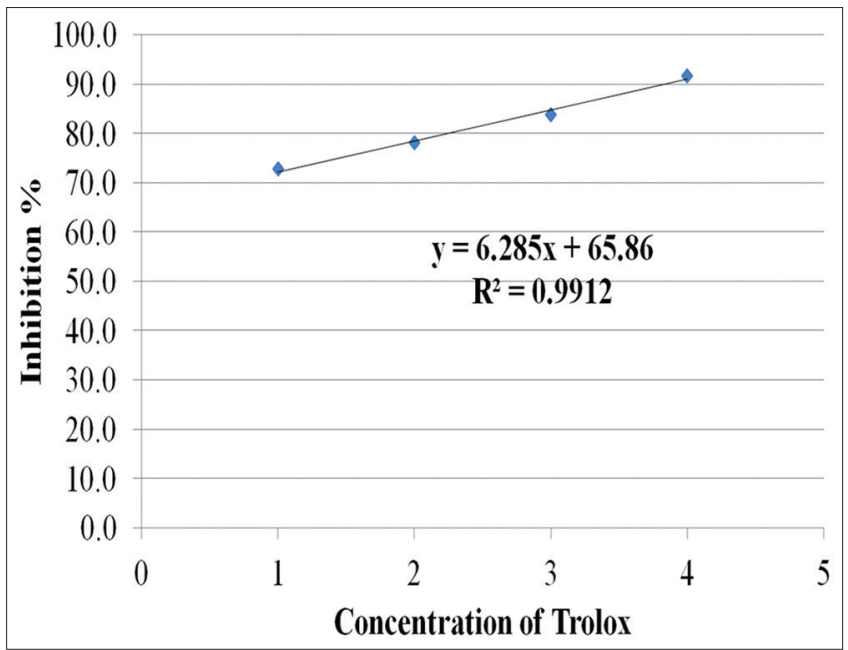

Fig. 2: Standard curve of extinction against trolox concentration

Table 1: DPPH free radical scavenging activity and $\mathrm{IC}_{50}$ values in different solvent extracts

\begin{tabular}{|c|c|c|c|c|c|c|}
\hline \multirow[t]{2}{*}{ Plant name } & \multirow[t]{2}{*}{ Extract } & \multicolumn{4}{|c|}{ DPPH inhibition percentage $\mu \mathrm{g} / \mathrm{mL}$} & \multirow[t]{2}{*}{$\mathrm{IC}_{50}$ values $(\mu \mathrm{g} / \mathrm{mL})$} \\
\hline & & 100 & 200 & 300 & 400 & \\
\hline \multirow[t]{3}{*}{ A. racemosa } & Methanol & $32.4 \pm 0.023$ & $35.4 \pm 0.020$ & $37.6 \pm 0.012$ & $40.4 \pm 0.026$ & $7.6 \pm 0.025$ \\
\hline & Chloroform & $30.4 \pm 0.026$ & $32.1 \pm 0.026$ & $34.9 \pm 0.020$ & $37.9 \pm 0.026$ & $8.8 \pm 0.032$ \\
\hline & Ethyl acetate & $28.0 \pm 0.038$ & $31.1 \pm 0.017$ & $32.9 \pm 0.012$ & $35.8 \pm 0.023$ & $9.6 \pm 0.035$ \\
\hline \multirow[t]{4}{*}{ S. uniflora } & Methanol & $28.7 \pm 0.029$ & $32.3 \pm 0.020$ & $35.1 \pm 0.020$ & $38.0 \pm 0.020$ & $8.0 \pm 0.030$ \\
\hline & Ethanol & $24.3 \pm 0.015$ & $26.9 \pm 0.015$ & $29.4 \pm 0.018$ & $38.4 \pm 0.025$ & $7.0 \pm 0.026$ \\
\hline & Chloroform & $40.9 \pm 0.023$ & $50.6 \pm 0.023$ & $66.4 \pm 0.032$ & $70.2 \pm 0.023$ & $1.8 \pm 0.017$ \\
\hline & Ethyl acetate & $28.5 \pm 0.020$ & $30.2 \pm 0.015$ & $31.8 \pm 0.015$ & $33.7 \pm 0.017$ & $13.3 \pm 0.036$ \\
\hline Ascorbic acid & & $70.3 \pm 0.017$ & $87.1 \pm 0.012$ & $89.6 \pm 0.018$ & $96.5 \pm 0.025$ & $1.5 \pm 0.025$ \\
\hline
\end{tabular}

*A. racemosa: Atalantia racemosa, S. uniflora: Senna uniflora. IC $_{50}$ values: Inhibitory concentration 50, DPPH: 1,1-diphenyl-2-picryl-hydrazyl, each value represents a mean \pm SE $(n=3)$

Table 2: ABTS free radical scavenging activity and $\mathrm{IC}_{50}$ values in different solvent extracts.

\begin{tabular}{|c|c|c|c|c|c|c|}
\hline \multirow[t]{2}{*}{ Plant name } & \multirow[t]{2}{*}{ Extract } & \multicolumn{4}{|c|}{ ABTS inhibition percentage $\mu \mathrm{g} / \mathrm{mL}$} & \multirow[t]{2}{*}{$\mathrm{IC}_{50}$ values $(\mu \mathrm{g} / \mathrm{mL})$} \\
\hline & & 100 & 200 & 300 & 400 & \\
\hline \multirow[t]{3}{*}{ A. racemosa } & Methanol & $73.0 \pm 0.029$ & $84.9 \pm 0.023$ & $91.8 \pm 0.017$ & $96.5 \pm 0.020$ & $2.2 \pm 0.020$ \\
\hline & Chloroform & $73.0 \pm 0.072$ & $85.2 \pm 0.019$ & $91.4 \pm 0.088$ & $96.3 \pm 0.012$ & $2.2 \pm 0.019$ \\
\hline & Ethyl acetate & $74.1 \pm 0.068$ & $81.5 \pm 0.07$ & $90.9 \pm 0.023$ & $97.3 \pm 0.076$ & $2.0 \pm 0.022$ \\
\hline \multirow[t]{4}{*}{ S. uniflora } & Methanol & $75.7 \pm 0.072$ & $83.9 \pm 0.07$ & $88.6 \pm 0.074$ & $94.7 \pm 0.051$ & $3.2 \pm 0.012$ \\
\hline & Ethanol & $75.4 \pm 0.096$ & $80.2 \pm 0.010$ & $86.7 \pm 0.021$ & $93.9 \pm 0.055$ & $3.0 \pm 0.018$ \\
\hline & Chloroform & $20.3 \pm 0.075$ & $30.9 \pm 0.08$ & $42.0 \pm 0.011$ & $50.9 \pm 0.049$ & $3.8 \pm 0.020$ \\
\hline & Ethyl acetate & $74.2 \pm 0.062$ & $80.6 \pm 0.06$ & $87.9 \pm 0.065$ & $91.2 \pm 0.052$ & $3.2 \pm 0.023$ \\
\hline Trolox & & $72.7 \pm 0.016$ & $78.0 \pm 0.018$ & $83.8 \pm 0.017$ & $91.7 \pm 0.015$ & $2.5 \pm 0.027$ \\
\hline
\end{tabular}

*A. racemosa: Atalantia racemosa, S. uniflora: Senna uniflora. $\mathrm{IC}_{50}$ values: Inhibitory concentration 50, ABTS: 2, 2'-azinobis, 3-ethylbenzothiazoline-6-sulfonic acid, each value represents a mean \pm SE $(n=3)$ 
Table 3: $\alpha$-amylase inhibitory activity (inhibition \%) and IC $_{50}$ values in different solvent extracts

\begin{tabular}{|c|c|c|c|c|c|c|}
\hline \multirow[t]{2}{*}{ Plant name } & \multirow[t]{2}{*}{ Extract } & \multicolumn{4}{|c|}{$\alpha$-amylase inhibition percentage $\mu \mathrm{g} / \mathrm{mL}$} & \multirow[t]{2}{*}{$\mathrm{IC}_{50}$ values $(\mu \mathrm{g} / \mathrm{ml})$} \\
\hline & & 100 & 200 & 300 & 400 & \\
\hline \multirow[t]{3}{*}{ A. racemosa } & Methanol & $63.6 \pm 0.012$ & $72.9 \pm 0.013$ & $80.8 \pm 0.012$ & $82.4 \pm 0.016$ & $0.5 \pm 0.015$ \\
\hline & Chloroform & $41.4 \pm 0.012$ & $57.9 \pm 0.015$ & $62.1 \pm 0.015$ & $66.0 \pm 0.019$ & $1.6 \pm 0.011$ \\
\hline & Ethyl acetate & $60.2 \pm 0.015$ & $69.9 \pm 0.015$ & $74.4 \pm 0.017$ & $79.0 \pm 0.017$ & $1.0 \pm 0.018$ \\
\hline \multirow[t]{4}{*}{ S. uniflora } & Methanol & $61.7 \pm 0.012$ & $68.1 \pm 0.012$ & $71.4 \pm 0.066$ & $80.7 \pm 0.015$ & $0.9 \pm 0.015$ \\
\hline & Ethanol & $41.2 \pm 0.014$ & $55.3 \pm 0.09$ & $59.1 \pm 0.025$ & $61.9 \pm 0.012$ & $1.8 \pm 0.018$ \\
\hline & Chloroform & $50.6 \pm 0.013$ & $54.4 \pm 0.013$ & $60.4 \pm 0.011$ & $74.7 \pm 0.015$ & $1.2 \pm 0.021$ \\
\hline & Ethyl acetate & $62.7 \pm 0.010$ & $67.1 \pm 0.010$ & $74.8 \pm 0.017$ & $79.6 \pm 0.09$ & $1.1 \pm 0.013$ \\
\hline Acarbose & & $52.0 \pm 0.014$ & $64.0 \pm 0.016$ & $70.0 \pm 0.012$ & $83.0 \pm 0.017$ & $0.7 \pm 0.015$ \\
\hline
\end{tabular}

$*$ A. racemosa: Atalantia racemosa, S. uniflora: Senna uniflora, $\mathrm{IC}_{50}$ values: Inhibitory concentration 50 , each value represents a mean \pm SE $(\mathrm{n}=3$ )

Table 4: $\alpha$-glucosidase inhibitory activity (inhibition $\%$ ) and $\mathrm{IC}_{50}$ values in different solvent extracts

\begin{tabular}{|c|c|c|c|c|c|c|}
\hline \multirow[t]{2}{*}{ Plant name } & \multirow[t]{2}{*}{ Extract } & \multicolumn{4}{|c|}{$\alpha$-glucosidase inhibition percentage $\mu \mathrm{g} / \mathrm{mL}$} & \multirow[t]{2}{*}{$\mathrm{IC}_{50}$ values $(\mu \mathrm{g} / \mathrm{mL})$} \\
\hline & & 100 & 200 & 300 & 400 & \\
\hline \multirow[t]{3}{*}{ A. racemosa } & Methanol & $69.1 \pm 0.07$ & $73.6 \pm 0.020$ & $78.9 \pm 0.012$ & $84.6 \pm 0.012$ & $2.6 \pm 0.013$ \\
\hline & Chloroform & $68.5 \pm 0.014$ & $82.5 \pm 0.015$ & $87.1 \pm 0.015$ & $88.9 \pm 0.015$ & $2.3 \pm 0.022$ \\
\hline & Ethyl acetate & $65.6 \pm 0.023$ & $78.9 \pm 0.015$ & $88.4 \pm 0.016$ & $91.1 \pm 0.018$ & $1.1 \pm 0.020$ \\
\hline \multirow[t]{4}{*}{ S. uniflora } & Methanol & $68.1 \pm 0.015$ & $77.4 \pm 0.015$ & $81.8 \pm 0.014$ & $87.4 \pm 0.013$ & $2.1 \pm 0.023$ \\
\hline & Ethanol & $67.7 \pm 0.010$ & $78.2 \pm 0.015$ & $81.7 \pm 0.015$ & $87.0 \pm 0.016$ & $2.1 \pm 0.012$ \\
\hline & Chloroform & $67.6 \pm 0.07$ & $76.9 \pm 0.012$ & $79.2 \pm 0.013$ & $82.8 \pm 0.018$ & $2.9 \pm 0.011$ \\
\hline & Ethyl acetate & $69.5 \pm 0.011$ & $79.5 \pm 0.012$ & $87.1 \pm 0.024$ & $88.9 \pm 0.021$ & $2.2 \pm 0.017$ \\
\hline Acarbose & & $40.0 \pm 0.013$ & $64.3 \pm 0.015$ & $70.3 \pm 0.014$ & $83.0 \pm 0.012$ & $1.4 \pm 0.018$ \\
\hline
\end{tabular}

${ }^{*}$ A. racemosa: Atalantia racemosa, S. uniflora: Senna uniflora. $\mathrm{IC}_{50}$ values: Inhibitory concentration 50 , each value represents a mean \pm SE $(\mathrm{n}=3$ )

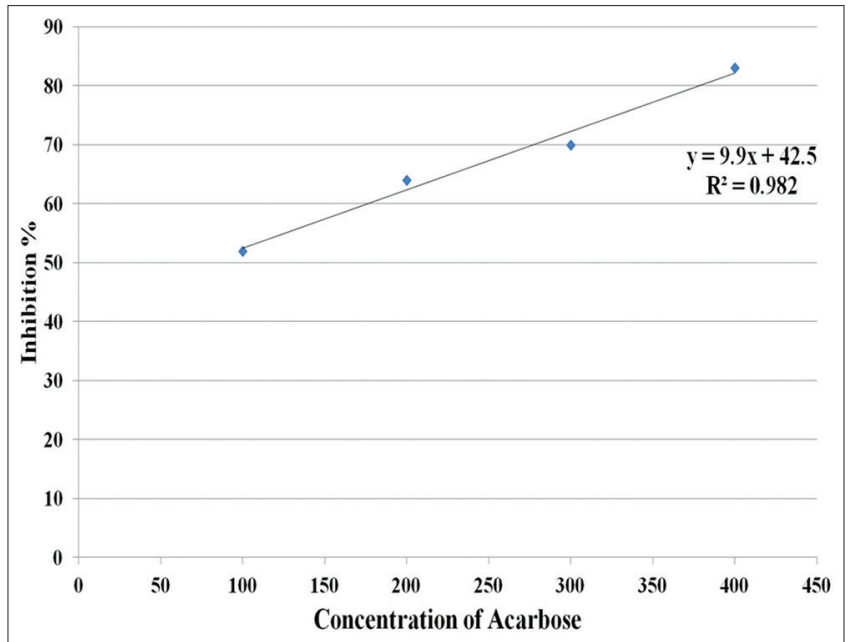

Fig. 3: Standard curve of extinction against acarbose concentration

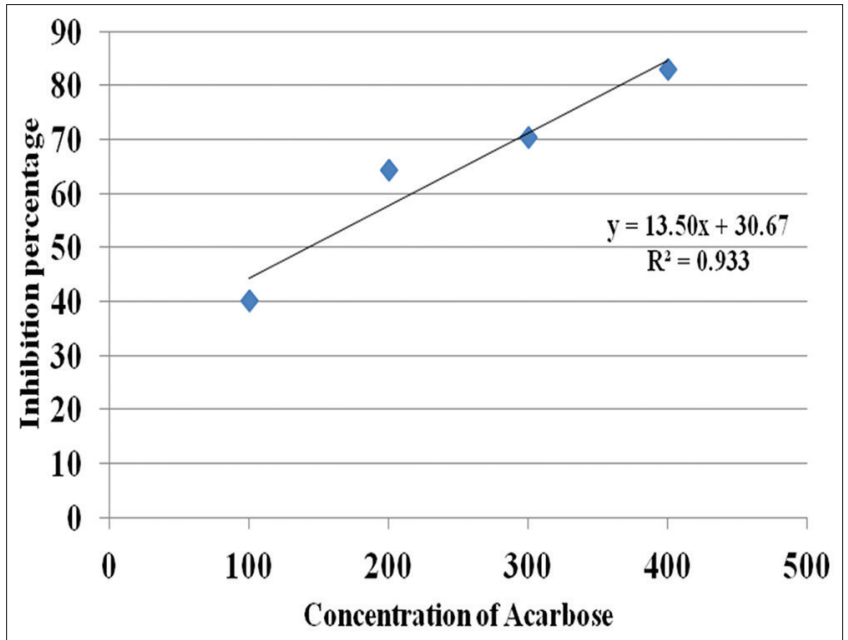

Fig. 4: Standard curve of extinction against acarbose concentration

\section{DISCUSSION}

The results of this study revealed that all the tested solvent extracts possess antioxidant activity. A. racemosa exhibited high antioxidant activity with a low $\mathrm{IC}_{50}$ value. Antioxidants derived from medicinal plants provide protection to cells by scavenging the excessive free radicals through offsetting ROS. This has been made possible due to the presence of certain bioactive substances; these compounds are might be responsible for antidiabetic activity in A. racemosa. Strong positive and significant correlation between radical scavenging activities with antidiabetic activities was observed. It has been also observed that the radical scavenging and antidiabetic activities increased with the increasing concentration of the plant extracts to a certain extent. Hence, it can be concluded that the antioxidant antidiabetic activities are said to be strongly dependent on the extract concentrations of the 
studied plants. There is no previous literature available so far about the antioxidant and antidiabetic activities of the studied plant so the mechanism by which $A$. racemosa exerted action may be due to its action on carbohydrate binding regions of $\alpha$-glucosidase enzyme, $\alpha$-amylase, and endoglucanases that catalyze hydrolysis of the internal $\alpha-1,4$ glycosidic linkages in starch and other related polysaccharides have also been targets for the suppression of postprandial hyperglycemia. This enzyme is responsible in hydrolyzing dietary starch into maltose which then breaks down to glucose before absorption.

\section{CONCLUSIONS}

The present work shows that $A$. racemosa is a medicinal plant with antioxidant and antidiabetic activities which could be utilized in several medicinal applications because of its effectiveness. Hence, the results of the present study may be useful to traditional healers and pharmaceutical industries. The results from the present study also indicated that it would be highly economical for the production of potential antioxidant and antidiabetic supplement(s). Authors are now involved in the identification and isolation of active compounds responsible for the antioxidant and antidiabetic activities of the plant.

\section{ACKNOWLEDGMENTS}

The authors are thankful to authorities of Savitribai Phule Pune University, for providing facilities and granting research fellowship.

\section{CONFLICTS OF INTERESTS}

All authors have none to declare.

\section{REFERENCES}

1. Mohan V, Sudha V, Radhika G, Radha V, Rema M, Deepa R. Geneenvironment interactions and the diabetes epidemic in India. Forum Nutr 2007;60:118-26.

2. American Diabetes Association. Diagnosis and Classification of Diabetes Mellitus. Diabetes Care 2009;32 Suppl 1:S62-7.

3. Bagchi D, Preuss HG. Obesity: Epidemiology, Pathophysiology, and Prevention. $2^{\text {nd }}$ ed. London, New York: CRC Press; 2012.

4. Suganya G, Sampath KP, Dheeba B, Sivakumar R. In vitro antidiabetic, antioxidant and anti-inflammatory activity of Clitoria ternatea L. Int J Pharm Pharm Sci 2014;6:342-7.

5. Priyanka J, Padma K. Alpha amylase inhibitory activity of different extract of bark of Albizia lebbeck (L.) Benth. Int J Pharm Pharm Sci 2017;9:119-22.

6. Modi P. Diabetes beyond insulin: Review of new drugs for treatment of diabetes mellitus. Curr Drug Discov Technol 2007;4:39-47.

7. Sudha P, Zinjarde SS, Bhargava SY, Kumar AR. Potent $\alpha$-amylase inhibitory activity of Indian ayurvedic medicinal plants. BMC Complement Altern Med 2011;11:5.

8. Grover JK, Vats V, Rathi SS, Dawar R. Traditional Indian antidiabetic plants attenuate renal hypertrophy, urine volume and albuminuria in streptozotocin induced diabetic mice. J Ethnopharmacol 2001;76:233-8.

9. Murai A, Iwamura K, Takada M, Ogawa K, Usui T, Okumira J. Control of postprandial hyperglycemia by galactosyl maltobionolactone and its novel anti-amylase effect in mice. Life Sci 2002;71:1405-15.

10. Chinnappan A. Ethnomedicinal plants used for the treatment of snake bites by Malayali tribal's and rural people in Salem district, Tamil Nadu, India. Int J Biosci 2013;3:42-53.

11. Sukumaran S, Raj AD. Medicinal plants of sacred groves in Kanyakumari district Southern Western Ghats. Indian J Tradit Knowl 2010;9:294-9.

12. Pullaiah T. Encyclopedia of World Medicinal Plants. New Delh: Regency Publications; 2006. p. 1069-70.

13. Uphof JC. Dictionary of Economic Plants. Weinheim: Weinheim Publication; 1959.

14. Usha V, Bopaiah AK. Phytochemical investigation of the ethanol, methanol and ethyl acetate leaf extracts of six cassia species. Int J Pharm Biol Sci 2012;2:260-70.

15. Jai K, Disha J, Stephen P. Population dynamics of Parthenium hysterophorus (Asteraceae) and biological suppression through Casia occidentalis (Caesalpiniaceae). Turk J Bot 2011;35:111-9.

16. Cook T. The Flora of the Presidency of Bombay. Calcutta: Botanical Survey of India; 1903. p. 187.

17. Singh NP, Karthikeyan S. Flora of Maharashtra state, dicotyledonae. Vol. 1. Ranunculaceae-Rhizophoraceae. Calcutta: Bot Survey of India; 2000.

18. Tekao T, Watanabe N, Yagi I, Sakata K. A simple screening method for antioxidant and isolation of several antioxidants produced by marine bacteria from fish and shellfish. Biosci Biotechnol Biochem 1994;58:1780-3.

19. Kumarasamy Y, Byres M, Cox PJ, Jasapars M, Nahar L, Sarker SD. Screening seeds of some Scottish plants for free-radical scavenging activity. Phytother 2007;21:615-21

20. Brinda C, Mohan KR. Evaluation of antioxidant, antibacterial activity of ethanolic extract in the leaves of Combretum albidum and gas chromatography-mass septrometry analysis. Asian J Pharm Clin Res 2016;9:325-9

21. Re R, Pellegrini N, Proteggente A, Pannala A, Yang M, Rice-Evans C. Antioxidant activity applying an improved ABTS radical cation decolorization assay. Free Radic Biol Med 1999;26:1231-7.

22. Sriram PG, Archana P, Srinivasan PT, Subramanian S. Studies on the phytochemical screening and free radical scavenging potentials of Solanum nigrum leaves extract. Asian J Pharm Clin Res 2016;9:316-21.

23. Adisakwattana S, Ruengsamran T, Kampa P, Sompong W. In-vitro inhibitory effects of plant-based foods and their combinations on intestinal $\alpha$-glucosidase and pancreatic $\alpha$-amylase. BMC Complement Altern Med 2012;12:1-5.

24. Jayashree D, Kalita MC. In vitro hypoglycaemic evaluation of seven culinary plants of North East India against Type 2 diabetes. Asian J Pharm Clin Res 2016;9:209-12.

25. Kwon YI, Apostolidis E, Shetty K. In vitro studies of egg plant (Solanum melongena) phenolics as inhibitors of key enzymes relevant for Type 2 diabetes and hypertension. Bioresour Technol 2008;99:2981-8.

26. Amutha K, Godavari A. In-vitro antidiabetic activity of n-butanol extract of Sesamum indicum. Asian J Pharm Clin Res 2016;9:60-2. 